\title{
Evolution of surgical techniques for atrial septal defect repair in adults: A 10-year single-institution experience
}

\author{
Koray Ak, MD, Tayfun Aybek, MD, PhD, Gerhard Wimmer-Greinecker, MD, PhD, Feyzan Özaslan, MD, \\ Farhad Bakhtiary, MD, Anton Moritz, MD, PhD, and Selami Dogan, MD
}

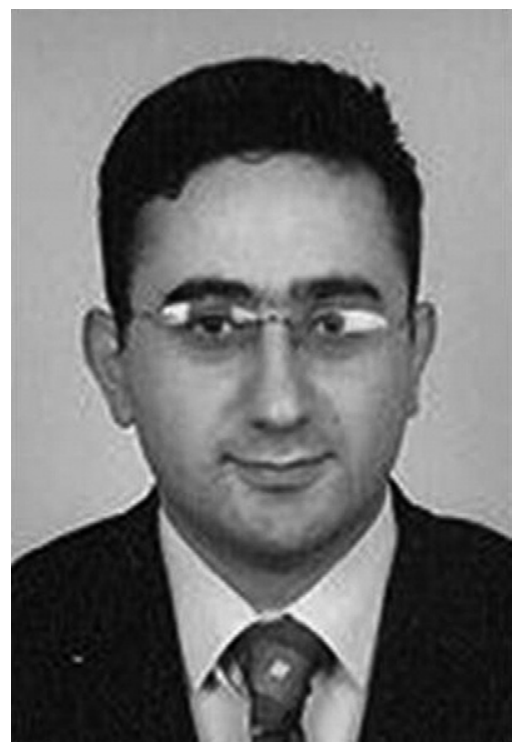

Dr Ak

Objective: We retrospectively analyzed our experience in atrial septal defect repair with varied minimally invasive surgical approaches.

Methods: From 1997 to 2006, 64 patients underwent surgical repair of atrial septal defects in our center. Patients were grouped into four groups according to the approach used; group $1(\mathrm{n}=16)$, partial lower sternotomy; group $2(\mathrm{n}=20)$, right anterior small thoracotomy with transthoracic clamping; group $3(n=4)$, right anterior small thoracotomy with endoaortic balloon clamping; and group $4(n=24)$, totally endoscopic approach with the use of the da Vinci surgical system (Intuitive Surgical, Mountain View, Calif). Preoperative diagnosis was a large secundum type atrial septal defect in 60 patients, primum type in 3 patients, and sinus venosus type in 1 patient.

Results: Complete atrial septal defect closure was verified by intraoperative transesophageal echocardiography in all patients. There was neither perioperative mortality nor major complication. Groups 3 and 4 had significantly longer aortic crossclamp, cardiopulmonary bypass, and skin-to-skin operative times than had groups 1 and $2(P=.000)$. All groups had similar ventilation time, postoperative drainage, and intensive care unit and hospital stays. Only 2 patients in group 4 were converted to the minithoracotomy owing to endoaortic balloon failure. During the follow-up of $30 \pm 24.3$ months, 1 patient in group 3 was reoperated on owing to significant residual shunting.

Conclusions: All types of atrial septal defects can be repaired via those four different approaches as safely as can be done by the conventional technique. General complications during surgical procedures are negligible. These approaches may be considered a standard treatment and an adjunct to transcatheter treatment options in atrial septal defect repair.

From the Department for Thoracic and Cardiovascular Surgery, Johann Wolfgang Goethe University, Frankfurt/Main, Germany.

Received for publication Feb 18, 2007; revisions received March 29, 2007; accepted for publication April 9, 2007.

Address for reprints: Koray Ak, MD (E-mail: akkoray@ hotmail.com).

J Thorac Cardiovasc Surg 2007;134:757-64

$0022-5223 / \$ 32.00$

Copyright (C) 2007 by The American Association for Thoracic Surgery

doi:10.1016/j.jtcvs.2007.04.004

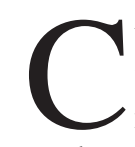
urrently, there is a growing interest in minimally invasive approaches in all fields of cardiac surgery. One of the most important principles to achieve minimally invasive procedures is to operate through limited incisions. Currently, a variety of cardiac procedures have been performed successfully via these limited incisions. Supposed benefits of these approaches are reduced surgical trauma, less postoperative pain, and faster postoperative convalescence. ${ }^{1-7}$ With the recent advance in the development of appropriate accessory technology, such as alternative methods of vascular cannulation for cardiopulmonary bypass (CPB) and endoscopic instrumentation using robotic telemanipulation, these small access approaches have been refined to a high level of performance. Minimally invasive surgical techniques for atrial septal defect (ASD) repair become quite popular in the past 2 decades, including partial sternotomies, different small thoracotomies, and totally endoscopic approaches. Totally endoscopic atrial septal repair (TEASR) has been demonstrated to be safe with a considerable reduction of surgical invasiveness. ${ }^{8}$ 

Abbreviations and Acronyms
ACC = aortic crossclamping
ASD $=$ atrial septal defect
$\mathrm{CPB}=$ cardiopulmonary bypass
ICS = intercostal space
PLS = partial lower sternotomy
RAST = right anterolateral small thoracotomy
TEASR = totally endoscopic atrial septal repair
TEE $=$ transesophageal echocardiography

This trend toward minimally invasive surgical ASD repair has been further supported by progress in competitive interventional methods, and this has even compelled the surgical effort to reduce surgical invasiveness to a minimal degree. During the past 10 years, full sternotomy technique for ASD closure, therefore, has been almost abandoned in our institution and replaced by three different minimally invasive surgical techniques: (1) partial lower sternotomy (PLS), (2) right anterolateral small thoracotomy (RAST), and (3) TEASR. In this report, we retrospectively analyzed our clinical experience with minimally invasive ASD closure. Our primary objectives in this study were to describe the evolution of surgical techniques in ASD repair and to document the impact of each individual technique on early postoperative outcome.

\section{Patients and Methods}

Sixty-four patients referred to our center for surgical closure of different types of ASDs from January 1997 to December 2006 were included. Patients were retrospectively divided into four groups according to the surgical approach and the perfusion technique used for ASD repair: group $1(\mathrm{n}=16)$ consisted of patients operated on by the PLS approach, group $2(\mathrm{n}=20)$ comprised patients operated on by the RAST approach with transthoracic clamping for aortic occlusion (RAST + transthoracic clamping, also called the Chitwood technique $\left.{ }^{2}\right)$, group $3(n=4)$ consisted of patients operated on by the RAST approach combined with the port-access system for CPB and aortic crossclamping (ACC) (RAST + endoclamping), and group $4(\mathrm{n}=24)$ consisted of patients operated on by a totally endoscopic approach (TEASR). The choice of minimally invasive surgical approach was based first on availability of robotic technology after August 1999, second on the personal preference of the patient for a particular approach, and last on the gender of the patient, that is, the PLS approach was used for male patients whereas the RAST approach was generally preferred by female patients for cosmetic reasons. Informed consent was obtained from all patients preoperatively.

Preoperative diagnosis of ASD, defect size, ratio of pulmonary flow to aortic flow, shunt flow volume, and pulmonary artery pressure measurements were performed by preoperative transthoracic echocardiography and transesophageal echocardiography (TEE). Shunt flow volume can be estimated using the area of the defect and the velocity time integral of the shunt flow measured with the Doppler beam parallel to shunt direction as described. ${ }^{9}$
Right heart catheterization was not routinely performed. All patients older than 35 years of age underwent coronary angiography to rule out concomitant coronary artery disease. As a policy, routine Doppler ultrasonography was performed preoperatively to rule out peripheral vascular disease of the iliac and femoral vessels for peripheral arterial cannulation, and patients with small or severely atherosclerotic femoral arteries were excluded from groups 2, 3, and 4. Also, patients with calcified and severely atherosclerotic ascending arch or descending aorta on TEE were excluded from groups 3 and 4 . All patients underwent pulmonary function testing preoperatively to assess whether single-lung ventilation would be feasible.

Demographics and preoperative characteristics of all patients are summarized in Table 1. Preoperative diagnosis was secundum type ASD in all patients, except ostium primum type defect and cleft mitral valve in 2 patients in the PLS and 1 patient in the RAST group and sinus venosus type defect in 1 patient in the TEASR group. Additionally, 3 patients had interatrial septal aneurysm ( 2 in the RAST + transthoracic clamping and 1 in the TEASR group), 1 patient had a left atrial myxoma $(10 \times 8 \mathrm{~mm})$ in the TEASR group, and 3 patients had multiperforated defects in the TEASR group. The type and size of ASD did not alter our surgical policy. All operations were performed by two senior surgeons. ASD repair was performed by either direct suturing or a patch (pericardial or Dacron). After weaning from CPB, TEE was routinely performed to check for any residual shunting.

\section{Anesthesia}

Anesthesia was induced with etomidate, sufentanyl, and pancuronium and maintained with sufentanyl and propofol in all patients. Double-lumen intubation for single-lung ventilation was used in groups 2,3 , and 4 , keeping the positive end-expiratory pressure of 7 to $8 \mathrm{~mm} \mathrm{Hg}$ on the left side. Both radial arteries were cannulated for invasive monitoring of the endoaortic clamp in groups 3 and 4 . TEE after induction was performed in all patients to confirm the diagnosis, to rule out any associated congenital disease and aortic insufficiency, and to control the intravascular placement of portaccess cannulas. In groups 3 and 4 , for selective venous drainage, a $19 \mathrm{~F}$ or $21 \mathrm{~F}$ venous cannula was placed percutaneously into the right jugular vein under half-dose heparinization before the operation.

\section{Operative Techniques}

$\boldsymbol{P L S}$. The patient was placed in the supine position on the operating table, and a 6- to 7-cm midline vertical skin incision was performed in the lower half of the sternum. An inverted J-shaped partial sternotomy was performed from the xiphoid to the right third intercostal space (ICS). The PLS was 2 to $3 \mathrm{~cm}$ longer than the skin incision. After systemic heparinization, central aortobicaval cannulation was done for $\mathrm{CPB}$. Both caval veins were encircled with silicone rubber vascular loops. After mild hypothermic $\mathrm{CPB}\left(32^{\circ} \mathrm{C}-34^{\circ} \mathrm{C}\right)$ and crossclamping of the aorta, intermittent cold blood cardioplegic infusion was administrated in an antegrade fashion into the aortic root. The surgical field was constantly flushed with carbon dioxide, according to our previously published technique to reduce gaseous emboli. ${ }^{10}$ Through a standard right atriotomy, the ASD was closed. Deairing was performed through the aortic root before aortic declamping. 
TABLE 1. Preoperative demographics of patients in the study

\begin{tabular}{|c|c|c|c|c|c|}
\hline & PLS (n = 16) & RAST $(n=20)$ & RAST + endoclamp $(n=4)$ & TEASR $(n=24)$ & $P$ value \\
\hline Age & $47.9 \pm 17.2$ & $48.2 \pm 16.6$ & $37.6 \pm 7$ & $45.5 \pm 17.0$ & .261 \\
\hline Gender (M/F) & $16 / 0$ & $7 / 13$ & $0 / 4$ & $10 / 14$ & \\
\hline Preoperative symptoms & $8(50)^{*}$ & $9(45)$ & $2(50)$ & $11(45.8)$ & .657 \\
\hline Chest pain & 2 & 2 & 0 & 2 & \\
\hline Palpitation & 1 & 1 & 0 & 3 & \\
\hline Dyspnea & 5 & 6 & 2 & 6 & \\
\hline Paradox embolism & $1(6.25)$ & $5(25)$ & 0 & $4(16.6)$ & .368 \\
\hline Comorbidity & $3(12.5)$ & $2(10)$ & $1(25)$ & $8(16.6)$ & .613 \\
\hline $\mathrm{DM}$ & 0 & 0 & 1 & 2 & \\
\hline HTN & 2 & 1 & 0 & 5 & \\
\hline COPD & 1 & 1 & 0 & 1 & \\
\hline NYHA class & $1.5 \pm 0.7$ & $1.7 \pm 0.7$ & $2.3 \pm 0.5$ & $1.4 \pm 0.5$ & .204 \\
\hline $\mathrm{EF}(\%)$ & $67.6 \pm 9.3$ & $64.3 \pm 9.9$ & $68.6 \pm 2.3$ & $67.1 \pm 8.8$ & .699 \\
\hline Shunt volume (\%) & $58.2 \pm 7.5$ & $53.9 \pm 16$ & $61 \pm 1.7$ & $56.2 \pm 12.2$ & .728 \\
\hline Mean PAP (mmHg) & $23.7 \pm 6.2$ & $22.1 \pm 8.2$ & $19.1 \pm 5.4$ & $19 \pm 6.7$ & .318 \\
\hline Size of defect $(\mathrm{mm})$ & $27.7 \pm 9.7$ & $24 \pm 9.8$ & $21.3 \pm 7.5$ & $24.6 \pm 10$ & .802 \\
\hline
\end{tabular}

PLS, Partial lower sternotomy; RAST, right anterolateral small thoracotomy; TEASR, totally endoscopic atrial septal repair; DM, diabetes mellitus; HTN, hypertension; COPD, chronic obstructive pulmonary disease; NYHA, New York Heart Association; $E F$, ejection fraction; $P A P$, pulmonary artery pressure. ${ }^{*}$ Numbers in parenthesis reflect percentages.

$\boldsymbol{R A S T}+$ transthoracic clamping. The patient was placed in a supine position with the right side of the chest elevated by $40^{\circ}$ and the pelvis remaining relatively flat to facilitate femoral cannulation. A small 6- to 7-cm anterolateral thoracotomy was performed in the right fourth ICS through a 5- to 6-cm right submammary skin incision. Particular care was applied to save the right internal thoracic artery. The right femoral vessels were exposed through a transverse incision for peripheral cannulation. A port-access $22 \mathrm{~F}$ or $25 \mathrm{~F}$ venous cannula (Ethicon, Somerville, NJ) was introduced for venous cannulation under TEE guidance. The femoral artery was cannulated with flexible arterial cannulas (20F to 22F; DPL; Medtronic, Inc, Minneapolis, Minn). After deflation of the right lung, the pericardium was opened longitudinally $2 \mathrm{~cm}$ anterior and parallel to the course of the phrenic nerve. A straight cardioplegia needle was secured to the aortic root for cardioplegia. Both caval veins were encircled by silicone rubber vascular loops. The ascending aorta was crossclamped transthoracically with a specifically designed clamp (Scanlan, St Paul, Minn) through a 5-mm incision in the third ICS. Cardiopulmonary perfusion, myocardial protection, and atriotomy were similar to the PLS technique. After repair of the defect, the deairing procedure was performed through the aortic root. To facilitate the deairing process, we carefully used intracardiac suction to prevent the emptying of the blood level in the left atrium. An intercostal block with bupivacaine was routinely administered in the third to fifth ICSs for pain control.

$\boldsymbol{R A S T}+$ endoclamping. The surgical approach, operative technique, and myocardial protection were completely similar to the RAST technique. A port-access perfusion system was used to establish CPB according to our previously published technique. ${ }^{3}$ In brief, the femoral vessels were exposed and prepared for peripheral cannulation. CPB was established with femoro-femoral cannulation via the Heartport Port-Access System (CardioVations of Ethicon, Inc, Norwalk, Conn). ACC was performed by insufflation of the endoaortic balloon clamp, and cardiac arrest was achieved by delivery of cold blood cardioplegic solution through the aortic root.

TEASR. TEASR was performed in a similar method to our previously published technique. ${ }^{11}$ In brief, the patient was positioned on the operating table with the right side elevated by $40^{\circ}$. After right lung deflation and insufflation of the thorax with carbon dioxide, a stereo-endoscope was inserted into the right fourth ICS between the midaxillary and anterior axillary line. The robotic arms were inserted through the third and sixth ICSs in the anterior axillary line. An additional 8-mm stab incision was necessary in the fifth ICS in the midaxillary line for transthoracic instrumentation. CPB was instituted via femoro-femoral cannulation with the Heartport Port-Access system (CardioVations of Ethicon, Inc, Norwalk, Conn, in 22 patients or Estech, Danville, Calif, in 2 patients). After endoaortic balloon clamping and cardioplegia, a standard right atriotomy was performed to repair the defect either directly or with a patch by the da Vinci Surgical system (Intuitive Surgical, Mountain View, Calif). The procedure was performed at moderate systemic hypothermia $\left(28^{\circ} \mathrm{C}\right)$.

\section{Statistical Analysis}

Statistical analysis was done by SPSS 10.0 version software (SPSS, Inc, Chicago, Ill). Data were defined as continuous and categorical variables. Continuous variables were expressed as mean \pm standard deviation and were compared by 1-way Bonferroni analysis of variance. Categorical variables were expressed as percentages and frequencies and were compared by means of $\chi^{2}$ tests.

\section{Results}

Preoperative characteristics of patients are summarized in Table 1. Patients in all groups were similar in age, symptomatology, comorbidities, ejection fraction, New York 
TABLE 2. Perioperative variables and early outcome of patients in the study

\begin{tabular}{lccccc}
\hline & PLS $\mathbf{n}=\mathbf{1 6})$ & RAST $(\mathbf{n}=\mathbf{2 0})$ & RAST + endoclamp $\mathbf{n}=\mathbf{4})$ & TEASR $\mathbf{n}=\mathbf{2 4})$ & $\boldsymbol{P}$ value \\
\hline ACC time (min) & $27.3 \pm 7.6$ & $29.8 \pm 24.7$ & $64.3 \pm 1.5$ & $63.6 \pm 20.4$ & .000 \\
CPB time (min) & $64 \pm 22.1$ & $74.6 \pm 41.2$ & $134.3 \pm 7.5$ & $135.2 \pm 39.2$ & .000 \\
Operation time (min) & $147.3 \pm 21.3$ & $160.5 \pm 40$ & $253.3 \pm 58.5$ & $262.6 \pm 60.6$ & .000 \\
Technique of repair & & & & & \\
$\quad$ Direct suturing/patch & $6 / 10$ & $7 / 13$ & $0 / 4$ & $20 / 4$ & .180 \\
Ventilation (h) & $6.3 \pm 1.1$ & $7.3 \pm 2$ & $8.6 \pm 2$ & $8.7 \pm 4.4$ & .434 \\
24-Hour drainage (mL) & $366.5 \pm 93.4$ & $407 \pm 365.6$ & $374 \pm 50$ & $454.3 \pm 394.1$ & .440 \\
ICU stay (h) & $18.2 \pm 5.4$ & $17.9 \pm 4.8$ & $20 \pm 4.3$ & $23.4 \pm 8$ & .689 \\
Hospital stay (d) & $8.2 \pm 2.2$ & $8.2 \pm 2.7$ & $9.6 \pm 2.3$ & $7.9 \pm 1.9$ & .9 \\
\hline
\end{tabular}

$P L S$, Partial lower sternotomy; RAMT, right anterolateral minithoracotomy; TEASR, totally endoscopic atrial septal repair; $A C C$, aortic crossclamping; $C P B$, cardiopulmonary bypass; ICU, intensive care unit.

Heart Association class, pulmonary artery pressure, shunt volume, and size of the defect preoperatively.

Perioperative data are given in Table 2. Patients in RAST + endoclamping and TEASR groups had significantly longer ACC, CPB, and skin-to-skin operative times than did the other groups $(P=.000)$. There were no differences between RAST + endoclamping and TEASR groups in terms of the ACC, CPB, and skin-to-skin operative times $(P=.999)$. Two $(8.3 \%)$ patients in the TEASR group were converted to RAST with the transthoracic clamping technique owing to endoaortic balloon malposition in the ascending aorta in 1 patient and kinking of the cardioplegia line in the other patient. Complete ASD repair without the presence of residual shunts was confirmed by TEE before weaning from bypass in all patients. Intraoperatively, in 1 patient in the RAST + endoclamping group, severe systemic hypoxia developed after institution of single-lung ventilation. TEE revealed reversal of the shunt from left to right to right to left. Ventilation of the left lung was found to be normal. It was thought to be an exaggerated hypoxic pulmonary vasoconstriction reaction resulting from single-lung ventilation and treated expeditiously by terminating singlelung ventilation for a short period and by intravenous corticosteroid application. Then, the procedure was completed successfully without conversion to the standard approach.

During the early postoperative period, there were no statistically significant differences among groups in terms of ventilation time, intensive care unit stay, 24-hour chest tube drainage, and hospital stay. We experienced a few complications during the early postoperative period but no major postoperative complication. One patient in the RAST + transthoracic clamping group and 1 in TEASR group had atrial tachyarrhythmias that were converted to normal sinus rhythm with medical therapy. Two patients, 1 in the RAST + transthoracic clamping group and 1 in the PLS group, had chronic atrial fibrillation preoperatively and remained in atrial fibrillation rhythm during the postoperative period. They received anticoagulation therapy with warfarin so- dium (Coumadin) after the second postoperative day. Two patients in the PLS group had a right-sided pneumothorax on the first postoperative day, treated successfully by placement of chest tubes. Owing to the increased postoperative drainage in 1 patient in the TEASR group, 3 units of erythrocyte suspensions were transfused. One patient in the RAST + transthoracic clamping group had a high fever resulting from Serratia marcescens bacteriemia during postoperative day 3 , which was successfully treated by the appropriate antimicrobial therapy. There were no wound healing problems at the thoracic or peripheral perfusion sites in any group. At discharge, all patients were in normal sinus rhythm except for 2 patients with chronic atrial fibrillation. No early mortality occurred. Echocardiographic follow-up at hospital discharge revealed normal atrial configuration without residual shunt.

After discharge, patients were transferred to specific rehabilitation centers. Then, they were routinely followed up by their family physicians. Although all approaches resulted in improved postoperative cosmesis, the best cosmetic result was seen after TEASR (Figure 1). All patients remained free of symptoms during the mean follow-up period of $30 \pm 24.3$ months (3-105 months), except for 1 patient in the TEASR group who had recurrent ASD after 2 years. On reoperation, she displayed a complete opening of the defect, probably resulting from failure of the suture. In groups 2, 3, and 4, there was no cases of venous congestion or ischemia of the lower extremity related to peripheral cannulation during the follow-up time.

\section{Discussion}

Standard surgical ASD repair with median sternotomy is a high-benefit and low-risk procedure with close to zero operative mortality. ${ }^{12}$ However, in this relatively younger and otherwise healthy patient population, more emphasis should be placed on postoperative cosmesis and quality of life. Recent advance in trancatheter closing devices has substantially shifted the treatment of secundum type ASDs from surgical repair to interventional closure. However, trans- 


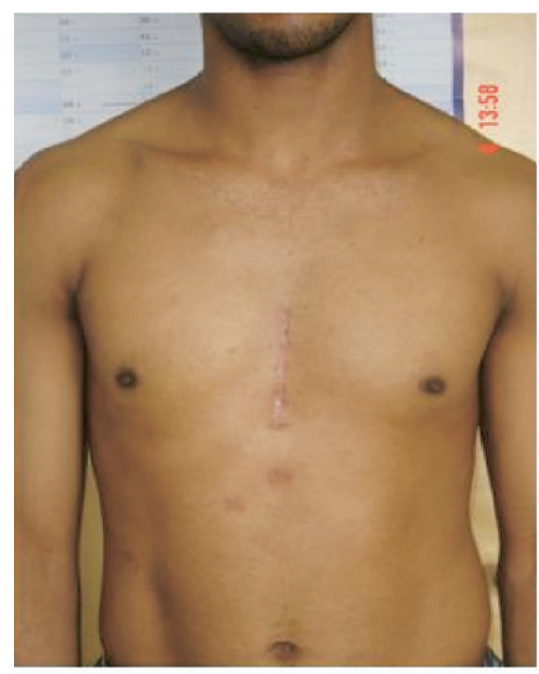

A

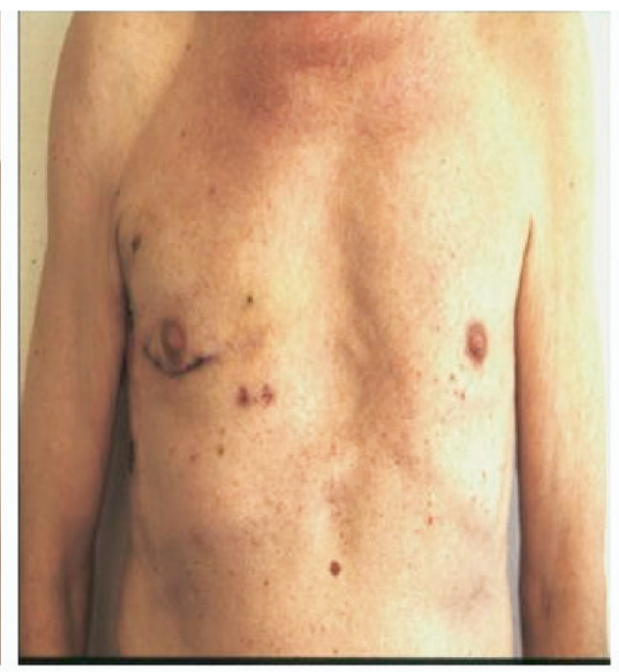

B

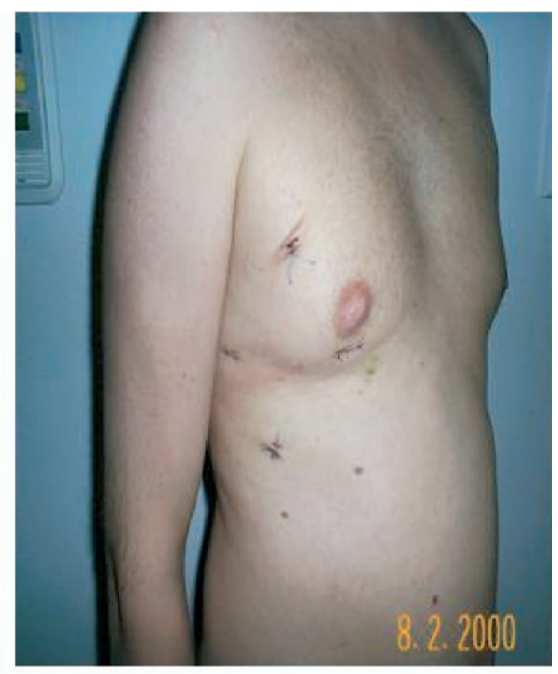

C

Figure 1. Photographic views of patients after PLS (A), RAST (B), and TEASR (C) approaches. PLS, Partial lower sternotomy; RAST, right anterolateral small thoracotomy; TEASR, totally endoscopic atrial septal repair.

catheter ASD closure has some obvious limitations. The procedural success rate in the transcatheter approach depends on the size and shape of the defect. Yet, the only ASD type suitable for transcatheter closure has been reported to be small secundum type ASDs. The presence of a large ASD with an insufficient rim to anchor the closure device, as well as a fenestrated or aneurysmal interatrial septum, has been shown to decrease the success rate of these procedures profoundly. ${ }^{13,14}$ Additionally, cerebral microembolism during the procedure, postprocedural thromboembolic risk, intracardiac shunt recurrence, injury to intracardiac structures, device dislocation, and subsequent peripheral embolization are documented potential complications. ${ }^{14-17}$ Therefore, surgery undoubtedly will continue to keep its place in the treatment of ASDs as an adjunct to the already existing percutaneous treatment options.

The main rationale behind minimally invasive cardiac surgery is to reduce surgical trauma and achieve faster postoperative convalescence and better cosmetic results compared with the conventional full sternotomy approach. In the late 1990s, as a result of technical innovation in peripheral CPB technology combined with the possibility of endoaortic clamping, remote cardiac arrest became feasible and thus enabled small access surgery. ${ }^{6,7}$ Introduction of robotic telemanipulation into cardiac surgery has even increased surgical dexterity and enabled surgeons to perform totally closed-chest intracardiac procedures. ${ }^{8}$

Most of the ASDs in this patient cohort were large (approximately $25 \mathrm{~mm}$ ) and some patients had complex defects, such as sinus venosus or ostium primum type ASDs plus cleft mitral valve. The series of patients described in this article represents a cohort that was not treatable by the percutaneous technique. This cohort demonstrates that all types of ASDs, regardless of size and morphologic type, can be reliably repaired by different minimally invasive surgical techniques: PLS, RAST (transthoracic or endoaortic clamping), and TEASR. Also, each technique offers relatively acceptable patient satisfaction in terms of cosmesis. During the past decade, several minimally invasive techniques, such as PLS, right anterolateral and subaxillary small minithoracotomies, and parasternal or subxiphoidal approaches, have been used for surgical ASD repair in current clinical practice. ${ }^{6,7,18-21}$ The PLS approach provides good exposure of great central vessels, and cannulation for CPB can be performed as easily as in the standard technique. There is no need for specially designed instruments, and resource use is not too high. In our experience, this approach yields higher cosmetic acceptance in male patients.

In female patients, however, the RAST approach, either transthoracic or endoclamping, for aortic occlusion has a high cosmetic acceptance and is referred to as the "bikini" line incision. ${ }^{6,7}$ RAST was reported to be a technically more challenging and time-consuming procedure in ASD repair in some reports. ${ }^{20}$ In our study, there was no statistically significant difference in operation, CPB, and ACC times between the PLS and the RAST + transthoracic clamping group. Patients in the RAST + endoclamping group had significantly longer operative, CPB, and ACC times than patients in the PLS and RAST + transthoracic clamp groups. The main reasons for this are the time-consuming placement of the endoaortic balloon, dislodgment of the balloon, and handling problems during cardiac arrest. ${ }^{3}$ Dif- 
ficulty of intracardiac deairing, defibrillation, and problems related to the peripheral cannulation are other known technical disadvantages of port-access perfusion. We did not experience any complication related to air embolization and peripheral cannulation, such as retrograde aortic dissection, limb ischemia, or wound healing problems at the femoral region in this patient cohort. These complications resulting from systemic arteriosclerosis are uncommon in a relatively young patient cohort like the ASD population with no peripheral vascular disease or other significant comorbidities. However, the presence of atherosclerotic iliofemoral arterial disease and small vessel size may complicate the procedure. Additionally, the use of port-access perfusion warrants more resource use. ${ }^{22}$ In this regard, the use of transthoracic clamping technique provides a simple and stable aortic occlusion, reduces problems associated with endoaortic clamping, and is more cost effective.

Another reported drawback of the RAST approach is phrenic nerve injury. We did not encounter any phrenic nerve damage in these patients. In our opinion, this complication can be prevented by defining the course of the phrenic nerve properly on the pericardium, pulling adequately on the pericardial stay sutures, and avoiding the use of topical cooling. ${ }^{14}$

TEASR has become the latest step in the surgical evolution of ASD repair. This is the only standardized and reproducible totally endoscopic cardiac procedure to date. ${ }^{8,11,23}$ In agreement with results from the literature, our results showed that TEASR is superior to the other minimally invasive approaches in terms of the degree of invasiveness, patient satisfaction, and cosmesis. ${ }^{11,23,24}$ Even though TEASR has some indisputable advantages over other surgical techniques in ASD repair, it has some apparent limitations. First, it is technically demanding and necessitates great expertise in both robotic and port-access perfusion surgical technology. The experience gained in portaccess surgery is a must and should be an initial step before switching to a robotic program in ASD repair. In our patient cohort, 2 patients were converted from the TEASR to the RAST + transthoracic clamping technique. Both conversions were associated with port-access system failures. As discussed in our previous report, ${ }^{11}$ stabilization of the endoaortic balloon in the aorta may be more difficult in patients with healthy and compliant aortas as in the ASD population. Second, costs for robotic surgery are exorbitantly high. However, some obvious benefits of robotic surgery, such as improvement in postoperative recovery and expeditious return to work, were claimed as evidence that a robotic approach is cost effective. ${ }^{24}$ Third, it remains a time-consuming procedure. Our experience and that of others showed that longer crossclamp, $\mathrm{CPB}$, and operative times can be shortened after a stepwise learning curve. ${ }^{11,23,24}$ Furthermore, longer operation times do not cause an additional disadvantage after TEASR, which may be attributed to the relatively younger age and lower incidence of comorbidities in this patient cohort. Last, there is no tactile feedback in robotic telemanipulation. Therefore, it sometimes may be difficult to estimate the tension over the suture line in the direct suturing technique in TEASR. One patient in our series required secondary reoperation owing to recurrence of the ASD. This complication may be a result of the overstretching of the suture line or insufficient knot tying.

Apart from cosmesis and chest wall stability, we did not find any difference in terms of the postoperative drainage, intensive care unit and hospital stay, and wound healing problems among the four groups. Some have shown that minimally invasive access provides additional advantages of shorter hospital stay, earlier return to normal activity, and better wound healing compared with the conventional sternotomy after ASD repair. ${ }^{7,18,19}$ These achievements may be related to limited surgical trauma and better stability of the bony thorax. More data with greater patient cohorts are necessary to make definite conclusions. In our study, although TEASR seems to be the least invasive approach, the early outcome in the TEASR group was similar to those of the RAST and PLS groups, as reported by others. ${ }^{25}$ This may be related to the longer $\mathrm{ACC}$ and $\mathrm{CPB}$ times in this group.

We did not perform postoperative pain scoring and quality of life analysis in this study. Median sternotomy, either complete or partial, is shown to be associated with less postoperative pain than the RAST. ${ }^{26}$ Even though the thoracotomy is limited, there is still a rib-spreading process and consequent intercostal nerve damage in the RAST technique. Walther and colleagues ${ }^{27}$ showed that in cardiac operations, either minimal access (partial sternotomy or minithoracotomy) or conventional approach, overall postoperative pain levels are low and lateral minithoracotomy approach is associated with slightly higher pain levels during the first 2 postoperative days. The routine intraoperative use of intercostal nerve blockage, cryoablation, or soft tissue retractors may help to minimize the degree of postoperative pain in patients undergoing RAST. ${ }^{27,28}$ In TEASR, there is obviously only minimal incisional trauma. Morgan and colleagues, ${ }^{25}$ showed that TEASR provides less postoperative pain and better quality of life than does the minithoracotomy or complete sternotomy.

However, pain perception and, to a lesser extent, quality of life are subjective issues rather than standardized. They may vary according to socioeconomic status, difference in sex and race, mental preparation of the patient for such surgical intervention preoperatively, and confidence of the patient in the procedure (especially in robotic procedures). Also, earlier mobilization and return to work may be a psychologic result of having a small incision in this otherwise healthy patient population. 
In 1 patient of the RAST + endoclamp group, we excountered hypoxia and reversal of the shunt owing to hypoxic pulmonary vasoconstriction after single-lung ventilation. Normally, hypoxic pulmonary vasoconstriction helps to maintain systemic oxygenation after single-lung ventilation. Hypoxic pulmonary vasoconstriction may cause severe right-to-left shunting of unoxygenated blood and eventually result in severe hypoxemia and hemodynamic instability, especially in patients with large ASDs. Additionally, several anesthetic agents such as propofol, lateral decubitus positioning, and high-frequency positive-pressure ventilation may exaggerate hypoxic pulmonary vasoconstriction during single-lung ventilation. ${ }^{29}$ Awareness of this rare complication in patients undergoing single-lung ventilation is essential for proper intraoperative management in ASD repair.

Owing to the fact that the intrathoracic dissection and trauma are limited, one of the benefits of these minimally invasive approaches may be the creation of fewer adhesions in the long term. This is particularly important in this patient population because they are relatively younger and carry a potential risk for subsequent surgical interventions such as coronary artery bypass grafting.

Our study has some obvious limitations. First, because of the retrospective nature of the study, we did not perform early postoperative pain scoring and quality of life analysis. However, these analyses would increase the impact and the statistical power of the study. Second, minimally invasive approaches always raise the issues of cost and length of hospital stay. In our study, the cost analysis was not performed. The length of hospital stay did not create a difference among the groups. However, in the German diagnosisrelated group health care system, the length of hospital stay and costs are affected by factors other than the postoperative recovery alone.

In conclusion, from our experience, surgical closure of ASDs with PLS, RAST, and TEASR techniques can be carried out as safely and effectively as is done in conventional surgery. These procedures may be considered as a standard treatment option in ASD repair. Of these, TEASR does offer the best cosmetic outcome. PLS and RAST techniques also provide good cosmesis and high patient satisfaction in young male and female patients, respectively. Increased cost, complexity, and need for expertise in the surgical approach are the major drawbacks of TEASR and, to a lesser extent, RAST and endoclamp technique. The cosmetic appeal of these procedures should be weighted against their financial and technical disadvantages in selection of a particular surgical strategy for ASD repair.

\section{References}

1. Marc MJ. Minimally invasive cardiac surgery. Surg Endosc. 2006;20: S448-92.
2. Chitwood WR Jr, Elbeery JR, Chapman WH, Moran JM, Lust RL, Wooden WA, et al. Video-assisted minimally invasive mitral valve surgery: the micromitral operation. J Thorac Cardiovasc Surg. 1997; 113:413-4.

3. Wimmer-Greinecker G, Dzemali O, Aybek T, Keller H, Mierdl S, Moritz A, et al. Perfusion strategies for minimally invasive cardiac surgery. Multimedia Manual of Cardiothoracic Surgery/doi: 10.1510/ mmcts.2005.001206.

4. Doll N, Borger MA, Hain J, Becerius J, Walther T, Gummert JF, et al. Minimal access aortic valve replacement: effects on morbidity and resource utilization. Ann Thorac Surg. 2002;74:S1318-22.

5. Dogan S, Aybek T, Risteski PS, Detho F, Rapp A, WimmerGreinecker G, et al. Minimally invasive port access versus conventional mitral valve surgery: prospective randomized study. Ann Thorac Surg. 2005;79:492-8.

6. Däbritz S, Sachweh J, Walter M, Messmer BJ. Closure of atrial septal defects via limited left anterolateral thoracotomy as a minimal invasive approach in female patients. Eur J Cardiothorac Surg. 1999;15:18-23.

7. Ryan WH, Cheirif J, Dewey TM, Prince SL, Mack MC. Safety and efficacy of minimally invasive atrial septal defect closure. Ann Thorac Surg. 2003;75:1532-34.

8. Wimmer-Greinecker G, Deschka H, Aybek T, Mierdl S, Moritz A, Dogan S. Current status of robotically assisted coronary revascularization. Am J Surg. 2004;188:76S-82S.

9. Mehta RH, Helmcke F, Nanda NC, Hsiung M, Pacifico AD, Hsu TL. Transesophageal Doppler color flow mapping assessment of atrial septal defect. J Am Coll Cardiol. 1990;16:1010-6.

10. Martens S, Dietrich M, Doss M, Wimmer-Greinecker G, Moritz A. Optimal carbon dioxide application for organ protection in cardiac surgery. J Thorac Cardiovasc Surg. 2002;124:387-91.

11. Wimmer-Greinecker G, Dogan S, Aybek T, Khan MF, Mierdl S, Byhahn $\mathrm{C}$, et al. Totally endoscopic atrial septal repair in adults with computer-enhanced telemanipulation. J Thorac Cardiovasc Surg. 2003;126:465-68.

12. Horvath KA, Burke RP, Collins JJ Jr, Cohn LH. Surgical treatment of adult atrial septal defect: early and long-term results. J Am Coll Cardiol. 1992;20:1156-9.

13. Thomson JDR, Aburawi EH, Watterson KG, Doorn CV, Gibbs JL. Surgical and transcatheter (Amplatzer) closure of atrial septal defects: a prospective comparison of results and cost. Heart. 2002; 87:466-99.

14. Moritz A, Özaslan F, Dogan S, Abdel-Rahman U, Aybek T, WimmerGreinecker G. Closure of atrial and ventricular septal defects should be performed by the surgeon. J Intervent Cardiol. 2005;18:523-7.

15. Ferrari J, Baumgartner H, Tentschert S, Dorda V, Lang W, WillfortEhringer A, et al. Cerebral microembolism during transcatheter closure of patent foremen ovale. J Neurol. 2004;251:825-9.

16. Contrafouris CA, Chatzis AC, Giannopoulos NM, Milonakis M, Kousi T, Kirvassilis G, et al. Emergency surgical intervention for runaway atrial septal closure devices: a word of caution. J Thorac Cardiovasc Surg. 2006;132:1234-5.

17. Krumsdorf U, Ostermayer S, Billinger K, Trepels T, Zadan E, Horvath $\mathrm{K}$, et al. Incidence and clinical course of thrombus formation on atrial septal defect and patent foramen ovale closure devices in 1000 consecutive patients. J Am Coll Cardiol. 2004;43:302-9.

18. Hopkins RA, Bert AA, Buchholz B, Guarino K, Meyers M. Surgical patch closure of atrial septal defects. Ann Thorac Surg. 2004;77:2144-50.

19. Chang CH, Lin PJ, Chu JJ, Liu HP, Tsai FC, Chung YY, et al. Surgical closure of atrial septal defect: minimally invasive cardiac surgery or median sternotomy? Surg Endosc. 1998:12:820-4.

20. Formigari R, Donato RMD, Mazzere E, Corotti A, Rinelli G, Parisi F, et al. Minimally invasive or interventional repair of atrial septal defects in children: experience in 171 cases and comparison with conventional strategies. J Am Coll Cardiol. 2001;37:1707-12.

21. Cremer JT, Böning A, Anssar MB, Kim PY, Pethig K, Harringer W, et al. Different approaches for minimally invasive closure of atrial septal defects. Ann Thorac Surg. 1999;67:1648-52.

22. Watson DR. The clinical and financial impact of port access mitral valve surgery. Presented at the Second Annual Meeting and Scientific 
Sessions of the International Society for Minimally Invasive Cardiac Surgery, 1999 May 21-22; Paris, France.

23. Bonaros N, Schachner T, Oehlinger A, Ruetzler E, Kolbitsch C, Dichtl $\mathrm{W}$, et al. Robotically assisted totally endoscopic atrial septal defect repair: insights from operative times, learning curves and clinical outcome. Ann Thorac Surg. 2006;82:687-94.

24. Morgan J, Thorton BA, Peacock JC, Kohmoto T, Hollingsworth KW, Smith CR, et al. Does robotic technology make minimally invasive cardiac surgery too expensive? A hospital cost analysis of robotic and conventional techniques. J Card Surg. 2005;20:246-51.

25. Morgan J, Peacock JC, Kohmoto T, Garrido M, Schanzer BM, Kherani $\mathrm{AR}$, et al. Robotic techniques improve quality of life in patients undergoing ASD repair. Ann Thorac Surg. 2004;77:1328-33.
26. Niinami H, Ogasawarw H, Suda Y, Takeuchi Y. Single vessel revascularization with minimally invasive direct coronary artery bypass: minithoracotomy or ministernotomy? Chest. 2005;127:47-52.

27. Walther T, Falk V, Metz S, Diegeler A, Battellini R, Autschbach R, et al. Pain and quality of life after minimally invasive versus conventional cardiac surgery. Ann Thorac Surg. 1999;67:1643-7.

28. Becerius J, Metz S, Walther T, Doll N, Falk V, Diegeler A, et al. Pain is significantly reduced by cryoablation therapy in patients with lateral minithoracotomy. Ann Thorac Surg. 2000;70:1100-4.

29. Nagendran J, Stewart K, Hoskinson M, Archer SL. An anesthesiologist's guide to hypoxic pulmonary vasoconstriction: implications for managing single lung anesthesia and atelectasis. Curr Opin Anesthesiol. 2006;19:34-43. 